\title{
MULTIMERCADOS: UMA RECENTE E RENTÁVEL ALTERNATIVA DE APLICAÇÃO DENTRE OS FUNDOS DE INVESTIMENTOS
}

\section{MULTIMARKET: A RECENT AND PROFITABLE ALTERNATIVE APPLICATION AMONG THE INVESTMENT FUNDS}

Data do recebimento do artigo: 12/01/2012

Data do aceite do artigo: 13/04/2015

Data da publicação: 23/06/2015

José Flávio Messias Doutorado em Relações Internacionais - Pontifícia Universidade Católica, São Paulo Faculdade ENIAC

Andressa Chibane de Lucena Especialista em Finanças e Banking Universidade

Nove de Julho, São Paulo, Brasil

\section{RESUMO}

Uma maior rentabilidade dos Fundos Multimercados nas últimas décadas, deram à eles maior relevância em relação aos outros fundos de in vestimento. Buscando verificar quais os fatores que levaram este Fundo a desempenhar tal papel em nosso sistema financeiro, foi explanado neste trabalho a definição e histórico dos Multimercados, bem como suas estratégias de investimento e o perfil de seus gestores e investidores. Verificou-se ainda, a evolução do Pat rimônio destes Fundos em relação aos demais, baseando-nos em dados comparativos.

Palavras-Chave: Fundos de Investimento; Multimercado; Rentabilidade, alternativas de investimento.

\begin{abstract}
A better Hedge Funds performance on the last decades, give them a larger importance between the others mutual funds. With the goal of checking up witch causes leaded this Fund to have this position on our financial system, it has been exposed on this dissertation the Hedge Funds definition and history, as well their investment strategies and manager's and investor's profile. Whereas was confirmed its patrimonial evolution between the other funds based on comparative data.
\end{abstract}

Keywords: Mutual Funds; Hedge Funds; profitability; Investment alternatives. 


\section{1-INTRODUÇÃO}

O presente artigo pretende analisar o surgimento e a expansão dos investimentos realizados no segmento de Fundo Multimercado.

A partir da publicação da Instrução no 450 de 30 de Março de 2007, realizada pela Comissão de Valores Mobiliários - CVM, que alterou algumas das características e cria uma nova regulamentação para os Fundos de Investimentos no Brasil, se constituiu num novo marco para o mercado brasileiro de fundos de investimento, pois determina o início de sua internacionalização.

A principal motivação da CVM foi preparar a regulamentação dos fundos de investimento para um cenário de menor rentabilidade dos títulos públicos e consequentemente dos investimentos em "renda fixa".

Desta forma, verificamos que a relevância do tema consiste na análise da rentabilidade dos títulos de renda fixa no mercado nacional, num cenário de internacionalização das economias e dos fluxos de investimento, em que as taxas oferecidas constituem um fator extremamente relevante de atratividade de recursos, principalmente porque os mercados internacionais estão em queda.

Verificamos que existe uma multiplicidade de Fundos de Investimento no Mercado, que são propostos aos Investidores para que escolha $m$ aquele que seja mais rentável a fim de incorporá-lo ao seu patrimônio financeiro.

A questão central a ser aqui abordada é a de apresentar os Multimercados como uma alternativa mais viável para satisfazer os interesses do Investidor, dados que os Fundos tradicionais (Renda Fixa, Ações etc.) nem sempre apresenta a rentabilidade esperada.

\section{2-METODOLOGIA}

O foco deste artigo é realizar uma análise comparativa na que tange a constituição dos diversos fundos de renda existentes, assim como analisar o perfil das operações, as alternativas de investimento neste segmento e discutir os riscos envolvidos nessas operações.

Sendo assim, faremos um estudo mostrando a evolução do Fundo Multimercado a partir de sua constituição, constituindo uma boa opção de investimento num cenário de queda da rentabilidade apresentada pelos outros fundos de investimento.

Para a obtenção destes objetivos, algumas questões foram selecionadas de forma a dar consistência no atendimento deles e formar o corpo do trabalho. Estas questões foram assim equacionadas:

- Partindo da definição de Multimercados, apresentar sua classificação segundo a

Associação Brasileira das Entidades dos Mercados Financeiros e de Capitais - ANBIMA;

- -Mostrar a relevância deste Fundo e também como evoluiu historicamente, primeiro no Mundo para depois chegar no Brasil;

- Conceituar e mostrar como são as estratégias adotadas neste Fundo;

- Apresentar o perfil do seu Investidor e como deve atuar o Gestor dessa aplicação;

- Segundo a ANBIMA, destacar qual dos subtipos lidera o "ranking" de Multimercados;

- Verificar a evolução dos Multimercados em relação à s demais classes de Fundos, segundo a Tabela da ANBIMA. 
Ao final são apresentadas as conclusões em relação ao tema pesquisado, com suas possíveis aplicações práticas ou, até, com questionamentos que eventualmente possam gerar novos focos de pesquisa.

\section{3-FUNDOS MULTIMERCADO: UMA NOVA MODALIDADE DE INVESTIMENTO}

Em 30 de Março de 2007, a Comissão de Valores Mobiliários - CVM - publicou a Instrução $\mathrm{n}^{\circ} 450$, que altera algumas das características e cria uma nova regulamentação para os Fundos de Investimentos no Brasil, representando o início de sua internacionalização.

A principal motivação da CVM foi preparar a regulamentação dos fundos de investimento para um cenário de menor rentabilidade dos títulos públicos e consequentemente dos investimentos em "renda fixa".

Em função de sua motivação, as alterações dessa instrução se agrupam em três grandes conjuntos:

a) Melhorar o nível de informação dos investidores sobre os ativos e riscos das carteiras dos fundos;

b) Ampliar as alternativas de investimentos dos gestores, permitindo buscar maior competitividade e maior rentabilidade;

c) Assegurar que os distribuidores, gestores e administradores analisem cuidadosamente o perfil de risco dos investidores dos fundos.

Até a edição desta Instrução Normativa da CVM, o grande marco para a indústria de fundos brasileira era a Instrução $\mathrm{n}^{\circ} 409$ de agosto de 2004.

A Instrução Normativa $n^{\circ} 450$ atualiza e traz avanço $s$, mas já com a Instrução Normativa $\mathrm{n}^{\circ} 409$ a indústria ganhava transparência e aumentava a clareza das informações ao investidor. Naquele momento foram consolidadas as antigas normas de fundos de renda fixa, que eram de atribuição do Banco Central, e do s fundos de renda variável, antes normatizados pela CVM em um único instrumento.

O investidor foi o grande beneficiário da Instrução no 409 da CVM por se tratar de uma legislação moderna que lhe garante proteção adequada e informações mais claras para que invista em produtos que atendam realmente às suas necessidades. Nessa Instrução, a CVM fez a classificação dos fundos em sete categorias como foi visto inicialmente. É, portanto, a Instrução Normativa n ${ }^{\circ} 450$ da CVM que legisla nos dias de hoje estes Fundos de Investimento.

Segundo a Instrução $\mathrm{n}^{\circ} 409$ de 2004 da CVM, os Fundo s Multimercados constituem "uma espécie de condomínio que reúne recursos de um conjunto de investidores, com o objetivo de obter ganhos financeiros a partir da aquisição de uma carteira de títulos ou valores Imobiliários".

Multimercados são fundos que possuem políticas de investimento que envolvem vários fatores de risco, pois combinam investimento nos mercados de renda fixa, de câmbio, de ações, entre outros, e se utilizam ativamente de instrumentos de derivativos para alavancarem suas posições, ou para protegerem suas carteiras.

São fundos com alta flexibilidade de gestão. Por isso, dependem do talento do gestor na escolha do melhor momento para alocar recursos, na seleção dos ativos da carteira e no percentual do patrimônio que será investido em cada um dos mercados.

Atualizada pela deliberação $n^{\circ} 44$, de 24 de novembro de 2010 - a classificação dos Fundos de Investimento e especificamente a dos Multimercados, segundo a ANBIMA, é a que se segue: Macro; Trading; Multiestratégia; Multigestor; Juros e Moedas; Estratégia ENIAC Pesquisa, Guarulhos (SP), p. 1-11, v. 1, n. 1, jan.-jun. 2012 
Específica; Neutro; Direcional; Balanceados; Capital Protegido.

Essa classificação se baseia nas estratégias adotadas pelos gestores para atingir os objetivos dos fundos, que devem prevalecer sobre os instrumentos utilizados.

Passemos à conceituação de cada um deles:

1- Multimercados Macro

São Fundos que realizam operações em diversas class es de ativos (renda fixa, renda variável, câmbio, etc.), definindo as estratégias de investimento baseada em cenários macroeconômicos de médio e longo prazo prazos, atuando de forma direcional - Admite alavancagem.

2- Multimercados Trading

Fundos que concentram as estratégias de investimento em diferentes mercados ou classes de ativos, explorando oportunidades de ganhos originados por movimentos de curto prazo nos preços dos ativos - Admite alava ncagem.

3- Multimercados Multiestratégia

Fundos que podem adotar mais de uma estratégia de nvestimento, sem o compromisso declarado de se dedicarem a uma em particular. Admite alavancagem.

4- Multimercados Multigestor

Fundos que têm por objetivo investir em mais de um fundo, geridos por gestores distintos. A principal competência envolvida consiste no processo de seleção de gestores. Admite alavancagem.

5- Multimercados Juros e Moedas

Fundos que buscam retorno no longo prazo através de investimentos em ativos de renda fixa admitindo-se estratégias que impliquem risco de juros, risco de índice de preço ou risco de variações da moeda estrangeira . Excluem-se estratégias que impliquem exposição de renda variável (ações, etc). Admite alavancagem.

6- Multimercados Estratégia Específica

Fundos que adotam estratégia de investimento que implique riscos específicos, tais como commodities, futuro de índice. Admite alavancagem.

\section{7- Long and Short - Neutro}

Fundos que fazem operações de ativos e derivativos ligados ao mercado de renda variável, montando posições compradas e vendidas, com o objetivo de manterem a exposição neutra ao risco do mercado acionário. Os recursos remanescentes em caixa devem ficar investidos em operações permitida $\mathrm{s}$ ao tipo Referenciado DI. Admite alavancagem.

\section{8- Long and Short - Direcional}

Fundos que fazem operações de ativos e derivativos ligados ao mercado de renda variável, montando posições compradas e vendidas. O resultado deve ser proveniente preponderantemente, da diferença entre essas posições. Os recursos remanescentes em caixa devem ficar investidos em operações permitidas ao tipo Referenciado DI. Admite alavancagem.

\section{9- Fundos Balanceados}


Fundos que buscam retorno no longo prazo através de investimento em diversas classes de ativos (renda fixa, ações, câmbio, etc.) . Estes fundos utilizam uma estratégia de investimento diversificada e deslocamentos táticos entre as classes de ativos ou estratégia explícita de rebalanceamento de curto prazo. Também devem ter explicitado o mix de ativos com o qual devem ser comparados. Sendo assim, estes fundos não podem ser comparados a um indicado $\mathrm{r}$ de desempenho que reflita apenas uma classe de ativos (por exemplo: 100\% CDI). Não admite alavancagem.

\section{0- Fundos de Capital Protegido}

Fundos que buscam retornos em mercados de risco, procurando proteger, parcial ou totalmente, o principal investido.

No Brasil, como no Mundo, a magnitude dos recursos administrados e o número de participantes da indústria dos fundos de investimento têm sido cada vez mais expressivos nas economias.

Os fundos Multimercados ou "Hedge Funds" como são conhecidos no exterior, destacam-se pelo crescimento nos últimos anos e pelo elevado retorno: daí a sua relevância, a que já nos referimos no início deste trabalho.

Como bem observa Oliveira (2010, p. 2), eles chegaram a ficar conhecidos entre os pequenos investidores, para os quais os grandes bancos de varejo oferecem tais fundos, mostrando os ótimos retornos nos anos anteriores. $\mathrm{N}$ em sempre ficam claros os riscos, até porque é muito difícil detalhar minuciosamente as características dos fundos às pessoas leigas em mercado financeiro, a ponto de elas fazerem uso das informações.

Apesar disso, seria socialmente inadequado alijar esses investidores da oportunidade de obterem os elevado retornos dos fundos multimercado, que pode superar em muito o do Certificado de Depósito Interbancário (CDI).

Nos últimos anos, os fundos Multimercados foram colocados nas prateleiras de praticamente todos os bancos, especialmente nos grandes bancos comerciais, justificando assim a grande popularidade adquirida atualmente.

O seu surgimento no Brasil, com parte das características atuais, remonta aos anos

1990, mas somente nos últimos anos com a popularidade da Bolsa de Valores, devido aos elevados ganhos, e de outros investimentos mais sofisticados, como os derivativos, os Fundos Multimercado começaram a se tornar um dos principais tipos de fundos de investimento.

Segundo a ANBIMA, os Fundos Multimercado em termos de Patrimônio Líquido, ocupam a $2^{\mathrm{a}}$ colocação entre todos os tipos de fundo s, com $23 \%$ de representatividade nesta indústria, com patrimônio superior a $\mathrm{R} \$ 260$ bilhões, perdendo apenas para os conhecidos Fundos de Renda Fixa.

\section{4-EVOLUÇÃO HISTÓRICA}

Foi nos Estados Unidos, em 1949, que Alfred Winslow Jones constituiu o $1^{\circ}$ "Hedge Fund" (ou Multimercados), com uma estratégia em que isolava a capacidade de alocação de ativos, comprando os mais baratos e vendendo os mais caros: daí a origem do nome hedge fund. Ele queria retornos superiores e por isso a taxa cobrada da administração também seria superior, diferente. Esse fato fez com que fosse criada a "Taxa de Performance".

$\mathrm{Na}$ década de 1960 foi reconhecido o valor desses fundos e estima-se que foram criados mais de 150 desse tipo de Fundos. Nos anos seguintes, várias estratégias foram 
desenvolvidas para estes Fundos. Quando o mercado entrou em queda drástica (final dos anos 1960 até 1974) por terem ocorrido problemas de ordem social e econômica, vários Hedge Funds fecharam.

Em 2003, um estudo feito pelo Deutsche Bank mostrou que 8 dos 10 melhores investimentos de 1990 a 2002 foram Hedge Funds em termos de risco-retorno. Clientes Private (pessoas físicas de alto poder aquisitivo) respondem por mais de $70 \%$ do volume financeiro aplicado em Hedge Funds no mundo e os europeus são mais propensos a investir neles do que os americanos.

Somente a partir de 1995 é que no Brasil apareceram estes Fundos na forma que conhecemos hoje. Em 2002, o órgão controlador dele passou das mãos do Banco Central para a Comissão de Valores Mobiliários (CVM) que buscou sua simplificação, popularização e uma transparência maior.

Como o Brasil é um país com cultura de investimento diferente dos Estados Unidos e da Europa, a regulamentação destes Fundos foi mais rígida. Embora seja um investimento de risco, o investidor aqui não corre o risco de crédito em relação ao administrador, porque, ao contrário dos Estados Unidos, estes fundos são devidamente constituídos e controlados pelo Banco Central e a partir de 2004 pela CVM. Aqui, o investidor conta com um produto mais sofisticado e melhor supervisionado pelos órgãos do governo.

Em 2011, os Fundos Multimercado correspondem a mais de $20 \%$ dos investimentos em fundos, com um total de mais de 260 bilhões de reais investidos entre os diversos tipos.

\section{5-ESTRATÉGIAS DE MULTIMERCADOS}

Por conta de um mercado menor, mais controlado e com regulamento restrito, em nosso país, as estratégias utilizadas pelos Fundos Multimercado ainda são poucas.

As mais utilizadas são:

-Arbitragem: Procura explorar as distorções nos preços dos ativos, fazendo uso de modelos matemáticos.

-Equity Hedge: Aloca seus recursos em vários tipos de estratégias, mas relacionados exclusivamente com as operações com ativos do mercado de ações e seus derivativos.

-Long and Short: Fazem posições compradas e vendidas em ações e geralmente mantém a carteira neutra, isto é, o valor comprado é igual ao valor vendido.

-Macro: Toma posições direcionais compradas ou vendidas e m diversos ativos, e com prazo de maturação dos investimentos mais longo.

-Multi Estratégia: Possibilita alocar seus recursos nas determinadas estratégias aqui vistas, independentemente da classe de ativos.

-Trading: Realiza posições direcionais nos diversos mercado s, mas com duração curta podendo fazer compra e venda no mesmo dia.

\section{6-PERFIL DO GESTOR E DO INVESTIDOR NOS FUNDOS MULTIMERCADO}

Antes de analisarmos o Perfil do Gestor é necessário verificarmos que há dois tipos principais de gestores: os gestores dos Fundos de investimento (FIs) e os gestores dos Fundos de Investimento em Cotas de Participação dos Fis (FICs).

Pelo fato dos FIs responderem pela alocação de recursos de investidores institucionais (bancos comerciais, fundos de pensão, etc.), para u ma gestão mais transparente e que busque uma melhor diversificação da carteira de ativos, há uma equipe 
que avalia o risco de mercado detalhadamente, com acesso a todas as posições que compõem a carteira do Fundo.

Já os FICs, como investem em diversos FIs para a composição de sua carteira, também possuem equipes de risco de mercado, mas que por terem dificuldade de acesso às informações acerca da carteira dos FIs, muitas veze s não têm uma posição atualizada de sua exposição ao risco no mercado financeiro, bem como do efeito das estratégias adotadas na gestão do fundo.

Ao verificarmos estas peculiaridades dos Fis e dos FICs, podemos compreender quem são os principais gestores dos fundos multimercado em nosso Sistema Financeiro.

De acordo com pesquisa efetuada por Varga e Wengert (2010, p.17), em dezembro de 2008 os Bancos de Investimento, os Gestores Independentes e os Fundos de Pensão eram, respectivamente, os principais gestores dos FIs Multimercado, analisando-se o percentual de sua participação na administração dos fundos de investimento no mercado brasileiro.

No entanto, na mesma pesquisa, ao analisarmos os FICs, verifica-se que devido à menor participação destes em FIs Multimercado, diminuiu a porcentagem de Bancos de Investimento como gestores. Contudo, aumentou a participação de Fundos de Pensão.

A importante conclusão a que chega a pesquisa é de que os principais gestores deste tipo de fundo, no que se refere aos FIs, são os ges tores independentes, os quais têm aumentado sua participação no mercado brasileiro, apresentando um crescimento de $675 \%$, nos últimos 14 anos. Isto se dá porque os multimercados são fundos com estratégias mais sofisticadas de investimento e por consequência, envolvem maior risco.

Os autores verificam que com a maior internacionalização e sofisticação de nosso mercado, os grandes bancos comerciais que são os gestores da maioria dos fundos de investimento têm evitado gerenciar fundos de alto risco diretamente, uma vez que uma má administração pode impactar negativamente a imagem do banco, bem como repercutir em outros fundos que administram.

Por tal motivo, foram criados os FICs, administrados em sua maioria pelos bancos, que ao investirem em diversos FIs, diminuem sua exposição ao risco.

Quanto ao perfil do investidor, temos os Fundos de Pensão, Investidores Qualificados, Family Offices e o setor de Private Banking, responsáveis por investimentos em Fundos Multimercados, por buscarem uma melhor seleção de ativos em carteira para a minimização de risco com uma melhor rentabilidade.

Verifica-se tal afirmação, uma vez que as pessoas pertencentes ao segmento Private Banking, ou seja, pessoas físicas de alto poder aquisitivo, responderem por mais de $70 \%$ do volume financeiro aplicado em Multimercados no mundo.

\section{7-LIDERANÇA DE SUBTIPOS DE FUNDOS MULTIMERCADO SEGUN DO A ANBIMA}

A Tabela abaixo demonstra a evolução da Captação L íquida Mensal nos diversos subtipos de Fundos Multimercado no mês de Abril de 201:

Tabela 1- Captação Líquida Mensal por Subtipo de Multimercado - Mercado Doméstico (R\$ Milhões) - posição abril 2011

\begin{tabular}{|c|c|c|c|c|c|c|}
\hline Tipo & $01 / 2011$ & $02 / 2011$ & $03 / 2011$ & $04 / 2011$ & $\begin{array}{c}\text { Acumulado no } \\
\text { Ano }\end{array}$ & $\begin{array}{l}\text { Acumulado } \\
\text { em } 12 \text { Meses }\end{array}$ \\
\hline Balanceados & $-45,1$ & 8,2 & -39.7 & $-35,2$ & $-111,8$ & $-198,4$ \\
\hline Capital Proteqido & $-123,7$ & 421,6 & $-89,8$ & -38.9 & 169,2 & 30,0 \\
\hline Long And Short - Neutro & $-22,8$ & $-40,8$ & $-355,7$ & $-120,1$ & $-539,0$ & $-155,2$ \\
\hline Long And Short - Direcional & $-220,7$ & 197,7 & 306,6 & 86,9 & 350,4 & 1.387 .1 \\
\hline Multimercados Macro & $-841,0$ & $-28.978,8$ & $-595,7$ & $-295,1$ & -28.510 .8 & -29.487 .3 \\
\hline Multimercados Trading & $-14,5$ & $-19,3$ & 3,5 & 5,8 & $-24,4$ & 610,2 \\
\hline Multimercados Multiestrategia & $1.202,7$ & $1.331,2$ & -1.007 .8 & $8.932,1$ & $8.458,4$ & $33.553,2$ \\
\hline Multimercados Multigestor & 32,2 & $-549,5$ & $-184,0$ & 154,3 & $-547,0$ & 1.917 .5 \\
\hline Multimercados Juros e Moedas & $2.200,1$ & 63,8 & $4.846,9$ & $-3.109,3$ & $4.001,5$ & $13.008,4$ \\
\hline Multimercados Estratéqia Especifica & $-13,4$ & 75,0 & $-29,1$ & $-187,4$ & $-154,8$ & $-5.950,9$ \\
\hline
\end{tabular}


Analisando a Tabela acima no que se refere aos subtipos de Fundos Multimercado que estão na liderança nos dias de hoje, verificamos que:

a) O subtipo Multimercado Multiestratégia teve em Abril de 2011 o maior volume de captação, com 6,9 bilhões de reais, representando quase 45 vezes mais em relação ao volume do segundo subtipo;

b) Em segundo lugar, vem o Multimercado Multigestor, com captação de 154 milhões de reais, em Abril de 2011.

No acumulado do ano de 2011, a liderança ainda permanece com o Multimercado Multiestratégia. Contudo, em segundo lugar aparece o Multimercado Juros e Moedas.

Por fim, verificando-se o acumulado em 12 meses, o Multimercado Multiestratégia (Maio/2010 a Abril/2011), permanece na primeira posição, seguido do Multimercado Juros e Moedas.

Observa-se assim, que a liderança do Multimercado Multiestratégia nos períodos analisados deve-se à sua própria natureza, uma vez que foram adotadas estratégias de investimento adequadas, de acordo com o momento do cenário econômico.

No entanto, o Multimercado Juros e Moedas apresentou retração no mês de Abril/2011, uma vez que nestes últimos meses (abril a julho/2011) houve a queda da taxa cambial juntamente com uma redução dos indicadores de índices de preço aplicados em nossa economia.

A Tabela a seguir, demonstra a distribuição do Patrimônio Líquido Anual, por tipos de Fundos, de acordo com a classificação vigente da ANBIMA:

Tabela 2 - Patrimônio Líquido Anual - Distribuição \% por Tipo

\begin{tabular}{|c|c|c|c|c|c|c|c|}
\hline Periodo & Curto Prazo & $\begin{array}{c}\text { Referenciado } \\
\text { DI }\end{array}$ & Renda Fixa & $\begin{array}{l}\text { Multimer- } \\
\text { cado }\end{array}$ & Cambial & Açöes & $\begin{array}{l}\text { PL Tota! } \\
\text { em RS mithồes } \\
\text { constantes }\end{array}$ \\
\hline $12 / 1994$ & 0,00 & 0,00 & 92,70 & 0,00 & 0,00 & 7,24 & $195.938,6$ \\
\hline $12 / 1995$ & 0,00 & 0,00 & 83,45 & 13,24 & 0,37 & 2,77 & $229.556,7$ \\
\hline $12 / 1996$ & 0,00 & 0,00 & 83,55 & 11,18 & 1,22 & 3,89 & $393.223,2$ \\
\hline $12 / 1997$ & 0,00 & 0,00 & 67,22 & 20,50 & 0,79 & 11,23 & $406.626,4$ \\
\hline $12 / 1998$ & 0,47 & 27,62 & 46,83 & 15,14 & 0,82 & 8,53 & $456.106,8$ \\
\hline $12 / 1999$ & 1,56 & 33,61 & 38,67 & 15,55 & 1,14 & 9,01 & $571.504,6$ \\
\hline $12 / 2000$ & 3,32 & 30,46 & 40,92 & 14,95 & 1,36 & 8,12 & $699.894,1$ \\
\hline $12 / 2001$ & 0,00 & 29,34 & 37,42 & 22,46 & 2,12 & 7,14 & $734.999,8$ \\
\hline $12 / 2002$ & 0,00 & 24,65 & 33,17 & 25,51 & 1,68 & 8,74 & $599.315,6$ \\
\hline $12 / 2003$ & 2,74 & 18,85 & 33,47 & 27,54 & 1,31 & 7,87 & $808.431,9$ \\
\hline $12 / 2004$ & 3,66 & 18,00 & 30,26 & 28,57 & 0,78 & 8,17 & $856.586,4$ \\
\hline $12 / 2005$ & 2,75 & 20,24 & 39,66 & 17,24 & 0,29 & 8,32 & $1.020 .738,9$ \\
\hline $12 / 2006$ & 2,48 & 17,77 & 33,80 & 22,66 & 0,14 & 10,19 & $1.250 .414,0$ \\
\hline $12 / 2007$ & 2,39 & 14,56 & 29,98 & 23,78 & 0,06 & 15,51 & $1.430 .463,9$ \\
\hline $12 / 2008$ & 3,22 & 16,18 & 28,94 & 23,45 & 0,07 & 10,10 & $1.283 .366,1$ \\
\hline $12 / 2009$ & 3,38 & 13,96 & 26,26 & 23,72 & 0,05 & 11,90 & $1.627 .055,8$ \\
\hline $12 / 2010$ & 3,42 & 12,25 & 27,17 & 23,99 & 0,05 & 11,33 & $1.743 .085,2$ \\
\hline $04 / 2011$ & 4,13 & 12,18 & 29,43 & 22,44 & 0,05 & 10,58 & $1.773 .489,2$ \\
\hline
\end{tabular}

Fonte: ANBIMA

De acordo com a tabela acima, e os fatos acontecidos neste período, podemos sintetizar alguns pontos importantes: 
a) Na década de 1990, iniciaram-se as aplicações nos Fundos Multimercado, porém a liderança no mercado era a dos Fundos de Renda Fixa .

b) Com o advento do Plano Real, a partir de 1994, houve um controle do processo inflacionário, sendo que até 1999, houve redução daTaxa Básica de Juros (Selic) $\mathrm{e}$ manutenção de inflação baixa. Tais eventos explicam o fluxo migratório das reservas em Fundos de Renda Fixa para os Fundos Multimercado neste período, uma vez que era necessária uma alternativa de investimento que não contemplasse em sua totalidade os títulos públicos. A rentabilidade destes últimos decaiu, pois sua emissão é remunerada pela Selic. Ademais os títulos públicos / privados lastreados no IPCA (índice oficial de inflação), que também compõem a maioria dos Fundos de Renda Fixa, decaíram, pois o índice diminuiu aproximadamente 99,35\% entre 1995 e 2008.

c) Em janeiro de 1999, o governo brasileiro adotou o regime de câmbio flutuante, como instrumento de estabilidade econômica e financeira do país. Tal fato abriu oportunidade para o estabelecimento do investimento em moeda estrangeira como estratégia em fundos multimercado, uma vez que a taxa de câmbio sendo controlada pelo governo, faz com que o mesmo venha a emitir títulos públicos

indexados a ela, o que por sua vez vem sendo um instrumento de cobertura dos prêmios de risco para rolagem da dívida pública.

d) No período de 2.000 a 2.010, houve a consolidação d os Fundos Multimercado, estando os mesmos principalmente a partir de 2.007, em posição de quase empate com os Fundos de Renda Fixa.

e) Em 2008, com a crise do mercado de crédito imobiliário americano, que aumentou a volatilidade nos mercados acionários, com consequente aversão a risco pelos investidores, o Patrimônio Líquido dos Fundos Multi mercado é o que apresenta a menor queda dentre as modalidades de fundos. Isto porque, devido à mobilidade de gestão e diversas estratégias possíveis de investimento, mesmo com a queda nas posições, não houve um impacto expressivo. Tal ponderação, contudo, não podemos afirmar baseando-nos na tabela acima, no sentido de constatar se ocorreu porque houve um maior afluxo de investidores para esta modalidade ou por redução inexpressiva do Patrimônio devido a uma eficiente gestão dos ativos nestes Fundos.

f) No ano de 2.011, a posição mencionada se mantém, ficando os Fundos Multimercado em segundo lugar em relação à Renda Fixa.

Após a criação de diversas classes de Fundos por meio das normas da CVM, constata-se que nestas últimas duas décadas, os Fundos Multimercado foi a classe que mais evoluiu, com a migração do volume de recursos dos investidores principalmente em relação aos Fundos de Renda Fixa.

\section{8-CONSIDERAÇÕES FINAIS}

Existe uma multiplicidade de Fundos de Investimento no Mercado, que são propostos aos Investidores para que escolham aquele que seja mais rentável a fim de incorporá-lo ao seu patrimônio financeiro. Num sistema financeiro cada vez mais integrado, as conjunturas econômicas nacionais e internacionais afetam drasticamente a remuneração 
assim como as opções de investimento.

Como foi mencionada anteriormente, a adoção da política cambial flutuante pelo banco central nacional, proporcionou o estabelecimento do investimento em moeda estrangeira como estratégia em fundos multimercado, uma vez que a taxa de câmbio sendo controlada pelo governo, faz com que o mesmo venha a emitir títulos públicos indexados a ela, o que por sua vez vem sendo um instrumento de cobertura dos prêmios de risco para rolagem da dívida pública. Por outro lado, a crise financeira internacional, a volatilidade dos mercados, favoreceu a adesão de novos investidores à esta estratégia, ampliando os volumes de recursos direcionado à esta modalidade de investimento.

Basicamente, temos sete as classes dos fundos: Fundo de Curto Prazo, Fundo Referenciado, Fundo de Renda Fixa, Fundo de Ações, Fundo Cambial, Fundo de Dívida Externa e Fundo Multimercado. Através dos dados apresentados, verificamos a expansão significativa de algumas modalidades: Fundo DI que estava zerado em 1994 e passou a constituir 12,18\% do patrimônio total dos recursos investidos em 2011, os Fundos de Ações que subiram de 7,20\% para 10,58\%, Fundo Renda Fixa que caiu de 92,70\% para 29,43\%, uma queda vertiginosa; e o Fundo Multimercado, que saiu de uma posição zerada para atingir $22,44 \%$ do patrimônio.

Diante do exposto pode-se chegar a algumas conclusões derivadas do desenvolvimento do tema. São elas:

1- Os Fundos Multimercado ampliaram de forma eficaz as alternativas de investimento, propiciando maior competitividade entre os demais Fundos.

2- Trouxe tamanha rentabilidade que, satisfazendo os interesses dos investidores, ocupa atualmente o $2^{\circ}$ lugar entre os demais Fundos.

3- Historicamente, em curto espaço de tempo, tornou -se a escolha preferida da maioria dos investidores com vistas ao aumento de seu patrimônio financeiro, em decorrência de um menor risco mesmo em um cenário de alta volatilidade.

4- Sua diversificação e a adoção de múltiplas estratégias de investimento, mostraram-se adequadas para o êxito de seu desempenho.

5- A característica de flexibilidade permitiu ao Gestor adotar melhores estratégias na escolha dos Ativos que irão compor este Fundo.

Por fim, verifica-se que a evolução deste Fundo deve-se essencialmente à maturação do mercado financeiro nacional, dada a negociação transparente e em tempo real de diversas novas classes de Ativos, bem como ao desenvolvimento do sistema regulatório financeiro através das normas emanadas pela Comissão de Valores Mobiliários (CVM).

\section{REFERÊNCIAS}

ANBIMA (2011). Guia de Fundos. Acesso em 01 de junho de 2011, disponível em

ANBIMA http://www.comoinvestir.com.br/fundos/guia-defundos/classes_de_fundos/Paginas/default.aspx\#fragment-1

AZEVEDO, Hugo Daniel de Oliveira. 500 perguntas (e respostas) avançadas de Finanças: para profissionais do mercado. Rio de Janeiro: Elsevier, 2007, pp. 82-84

BRAGANÇA, Guilherme Lima. Como investidores de alta renda alocam sua riqueza no Brasil? Uma análise empírica com dados de fundos de investimento. Fundação Getulio Vargas, 2009. 
de Mercado de Fundos Multimercados Brasileiros. Insper Working Paper. IBMEC São Paulo, 2009.

FONSECA, Nelson Ferreira et al. Análise do Desempenho Recente de Fundos de Investimento no Brasil. Contabilidade Vista \& Revista, Vol. 18 (n. 1), pp. 95-116.

FRANCO, Delano; BRANCO, Roberto da Cunha Castello. Risco e retorno nos hedge funds brasileiros, in: Leal, R. Varga, G. (Eds). Gestão de Investimentos no Brasil, Keyword Editora, Rio de Janeiro, 2006.

NUNES, Sylvia Renata Pereira Aragão. Determinantes do crescimento das gestoras independentes de recursos no Brasil, pós plano real . Fundação Getulio Vargas, 2009.

OLIVEIRA, Fabio Avilla Barbosa de. Taxas de Administração e de Performance em Fundos Multimercados: uma Comparação dos Melhores e dos Maiores. Revista de Finanças Aplicadas, pp. 1-21, 2010.

VARGA, Gyogy; WENGERT, Maxim. The Growth and Size os the Brazilian Mutual Fund Industry. Acesso em 01 de junho de 2011, disponível em: http://ssrn.com/abstract=1575510. 